\title{
Dynamic Prediction and Optimization of Energy Efficiency Operational Index (EEOI) for an Operating Ship in Varying Environments
}

\author{
Chao Sun ${ }^{1,2}$, Haiyan Wang ${ }^{3, *}$, Chao Liu $^{2}$ and Ye Zhao ${ }^{4}$ \\ 1 Marine Engineering College, Dalian Maritime University, Dalian 116026, China; aba11@163.com \\ 2 Systems Engineering Research Institute, Beijing 100036, China; doming81@163.com \\ 3 Merchant Marine College, Shanghai Maritime University, Shanghai 200136, China \\ 4 Shanghai Rail Transportation Equipment Co., Ltd., Shanghai 200245, China; zhaoyeshanghai@163.com \\ * Correspondence: wanghaiyan@shmtu.edu.cn; Tel.: +86-21-3828-2974
}

Received: 22 September 2019; Accepted: 5 November 2019; Published: 8 November 2019

\begin{abstract}
The demands for lower Energy Efficiency Operational Index (EEOI) reflect the requirements of international conventions for green shipping. Within this context it is believed that practical solutions for the dynamic optimization of a ship's main engine and the reduction of EEOI in real conditions are useful in terms of improving sustainable shipping operations. In this paper, we introduce a model for dynamic optimization of the main engine that can improve fuel efficiency and decrease EEOI. The model considers as input environmental factors that influence overall ship dynamics (e.g., wind speed, wind direction, wave height, water flow speed) and engine revolutions. Fuel consumption rate and ship speed are taken as outputs. Consequently, a genetic algorithm is applied to optimize the initial connection weight and threshold of nodes of a neural network (NN) that is used to predict fuel consumption rate and ship speed. Navigation data from the training ship "YUMING" are applied to train the network. The genetic algorithm is used to optimize engine revolution and obtain the lowest EEOI. Results show that the optimization method proposed may assist with the prediction of lower EEOI in different environmental conditions and operational speed.
\end{abstract}

Keywords: merchant shipping; EEOI; genetic algorithms; neural networks; ship dynamics

\section{Introduction}

According to reports from the International Maritime Organization (IMO) [1], unless serious action is taken, annual $\mathrm{CO}_{2}$ emissions from the international shipping industry may increase by 1.5 3.5 times by 2050 . For this reason, vigorous developments regarding ship energy conservation and emission reduction technologies are essential [2,3].

The Energy Efficiency Operational Index (EEOI) was introduced by the IMO in 2009 to evaluate the $\mathrm{CO}_{2}$ emission performance of a ship. It served as a benchmark tool in monitoring ship and fleet efficiency performance. The indicator enables operators to measure the fuel efficiency of a ship in operation and to gauge the effect of any changes in operation [4]. The lower the EEOI is, the better the performance is.

The $\mathrm{CO}_{2}$ emission performance is directly affected by the environmental conditions and ship sailing state. However, the navigation environment varies with time and sea area. Therefore, the EEOI cannot be maintained at a lower level all the time. At the same time, fouling of the submerged part of the hull, degradation of the power plant and fluctuation of engine parameters will bring disadvantages to ship performance and enlarge the EEOI. Hence, there is a significant economic and environmental benefit to developing a general optimization method that may help to decrease the EEOI in varying environmental conditions. 
Harilaos N. Psarafits et al. stated that the ship speed is a decision variable for fuel consumption and emissions [5]. In fact, most methods applied to improve ship efficiency are to adjust ship speed. Route and speed optimization are operational procedures that may be used to improve shipping efficiency and EEOI. Inge Norstad et al. used a recursive smoothing algorithm to optimize the speed for ship routing and scheduling for a tramp ship [6]. Wang Shuai'an et al. conducted an in-depth analysis on the relationship between fuel consumption and ship speed based on the historical operational data of a container liner and optimized the ship speed by using nonlinear programming [7]. Ming-Chung Fang et al. applied a heuristic method to optimize ship routing in different weather conditions [8].

Lower steaming is another kind of validated method for decreasing fuel consumption and the EEOI. However, such operational strategy is limited by many factors, including the ETA (estimated time of arrival), fuel price, charter rates, influence of speed reduction on engine efficiency, and so forth $[9,10]$.

Joan P. Peterse developed a fuel consumption model by way of a machine learning method and ship navigation data [11]. Benjamin applied a neural network (NN) trained by noon report data to establish a propulsion power model under hydrostatic conditions [12]. Wang Kai et al. used the wavelet packet neural network to predict the sea conditions for a short-journey of a sailing ship and introduced a real-time energy efficiency model under predicted sea conditions [13].

This paper suggests a method that could be used to identify lower EEOI using real time operational data. An EEOI during a fixed time span is introduced to indicate fuel efficiency. A back propagation neural network, which is trained by navigation data, is used to predict ship speed and fuel consumption rate under real environmental conditions. The genetic algorithm is applied to obtain the lowest EEOI by optimizing the main engine revolution in a fixed time span in real conditions.

\section{EEOI Prediction Model}

In the guide issued by IMO in 2009 [14], it is shown that the EEOI can be expressed as:

$$
E E O I=\frac{M_{\mathrm{CO}_{2}}}{Q}=\frac{\sum_{j=1}^{n} F_{C_{j}} \cdot C_{F_{j}}}{M \cdot D},
$$

where $M_{\mathrm{CO}_{2}}$ is the carbon dioxide emissions ( $(\mathrm{t}), Q$ is the transport volume $(\mathrm{t}), F_{C_{j}}$ is the fuel consumption in the $j$ th voyage segment $(t), C_{F_{j}}$ is the carbon dioxide conversion factor in the $j$ th voyage segment, $M$ is the cargo capacity $(\mathrm{t})$, and $D$ is the transport distance (nm).

Transport volume is constant over a single voyage. Therefore, EEOI can be defined as the function of fuel consumption and transport distance. In practice, fuel consumption rate and ship speed vary. The fuel consumption over transport distance can be obtained by integration of the fuel consumption rate and ship speed. If a periodical time interval is applied to the integration, real time EEOI can be obtained, as shown in Equation (2):

$$
E E O I=\frac{C_{F} \int_{0}^{T} f_{C} d t}{M \int_{0}^{T} v_{s} d t},
$$

where $T$ is the cycle time $(\mathrm{s}), f_{C}$ is the fuel consumption rate $(\mathrm{t} / \mathrm{s})$, and $v_{S}$ is the ship speed $(\mathrm{m} / \mathrm{s})$.

There is no voyage segment parameter, because there is only one segment in the short cycle time during a single voyage. 


\subsection{Factors}

The navigation environment is a complex nonlinear system of systems, the interaction of which includes ship speed and fuel consumption (see Figure 1). For this reason, sufficient capture and clustering of big data analytics by neural networks is essential.

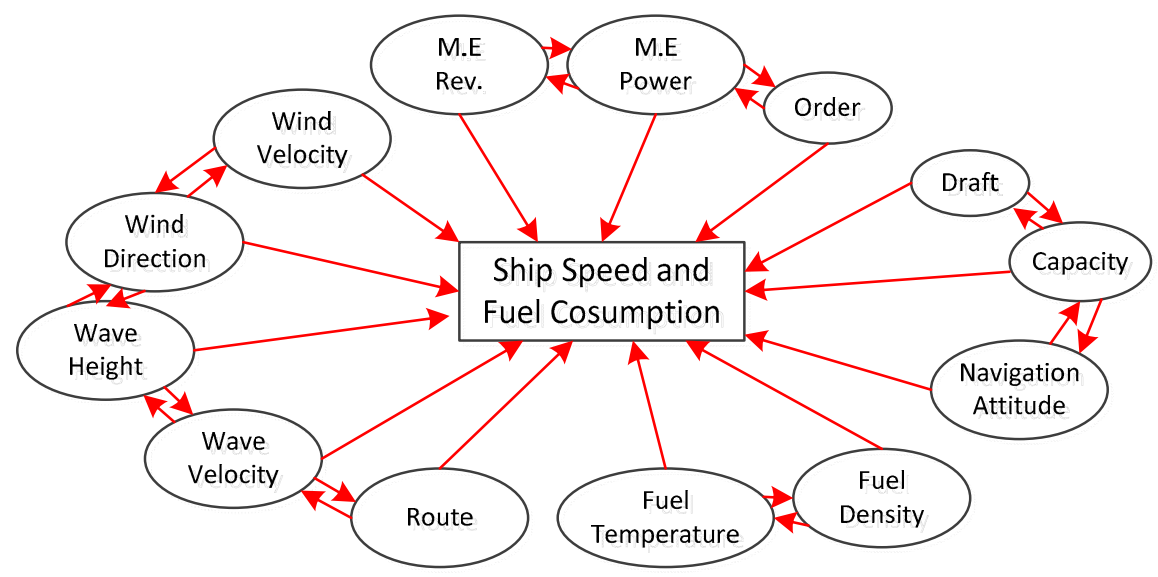

Figure 1. The main factors affecting ship speed and fuel consumption.

It is noted that ship draft, navigation attitude and route can be ignored because these parameters are constant over a voyage.

\subsection{Big Data Analytics}

Big data collected by the surveillance system are characterized by high Volume, low Veracity, high Variety, high Velocity, and high Value [15]. The navigation data collected during sailing have the same $5 \mathrm{~V}$ characteristics. Irrelevant data and errors may result in excessive noise signal traces. It is therefore essential to pre-process data by following the procedures outlines in Sections 2.2.1-2.2.4 below [16].

\subsubsection{Big Data Trimming}

Because the vessel may be docked or berthed, some subsets of the data are not only useless but also may damage the prediction ability of the model. Therefore, these subsets of the data must be pruned. As shown in Figure 2, the subsets of the data marked by the red ellipse are data collected in the time period when the ship is in a port or berthing state. The power of the main engine is zero in these states, and subsets should be pruned. In addition, the acceleration and deceleration processes at the beginning and end of the data segment should be removed because data do not contribute much in terms of modeling the entire voyage conditions.

\subsubsection{Big Data Synchronization}

Un-synchronized data, i.e. data that are not consistent in term of time scales, may result in inconsistent model input dimensions. In such situations, there is large probability that the input matrix may be singular matrix and not suitable for long-term vacancies.

From a practical perspective, each data block corresponds to a single trip (see Figure 3). Generally, all dimensional data should have the same length at the time axis. That is to say, the data from every factor should entirely overlap. Therefore, the method of synchronizing is to eliminate the part where the data from factors do not overlap and to choose valuable data from the overlapping zone. Then, an equal-length data set can be obtained, as shown in Figure 3. 


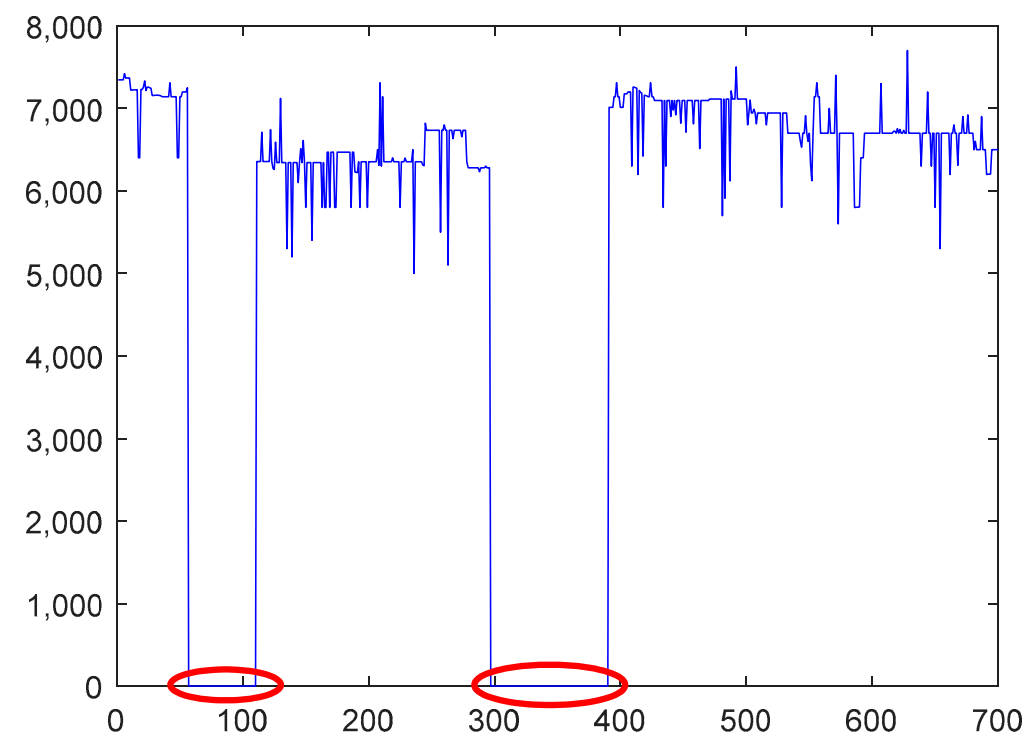

Figure 2. Data trimming diagram.

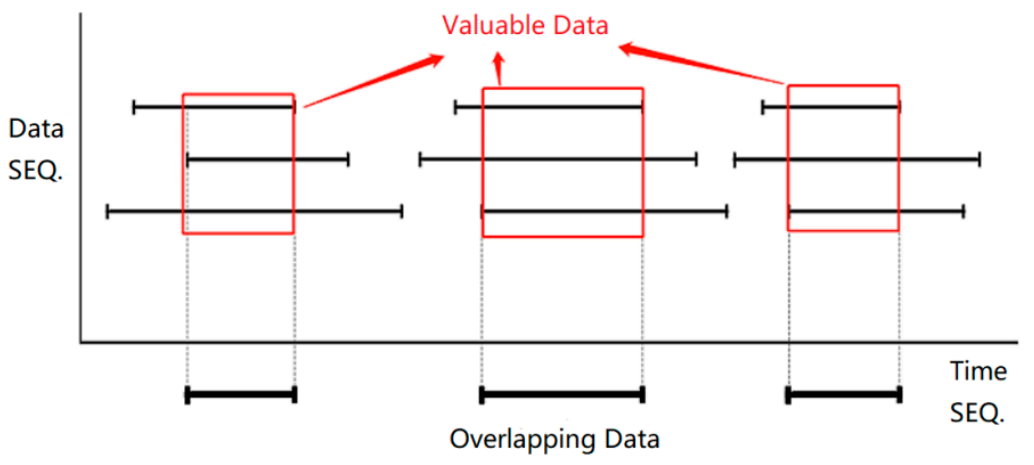

Figure 3. Data synchronization diagram.

\subsubsection{Big Data Normalization}

Big data are usually not within the same order of magnitude. If they are directly applied for training the neural network and the weights of the network nodes will vary greatly, bringing adverse effects to data analysis results. In order to eliminate the differences, the selected data must be normalized to achieve comparability among different scales. A common normalization process is to linearly scale the data and compress it to a closed interval [0,1], as shown in Equation 3:

$$
x^{*}=\frac{x-\min }{\max -\min },
$$

where $x^{*}$ is the normalized data value, $x$ is the original data value; max is the maximum possible value in the original data, and $\mathrm{min}$ is the minimum possible value in the original data.

\subsubsection{Dimensional Reduction Processing}

Based on knowledge from ship navigation dynamics and the actual operating experience of the ship, some variables of the input set may interact and relate to each other. To mine the main variables and extract key features, it is necessary to carry out dimensional reduction. 
In this paper, an intuitive correlation analysis method was used to reduce the dimensionality of data $[17,18]$. Accordingly, Equation 4 was used to calculate the correlation coefficient matrix $R$ :

$$
R=\left[\begin{array}{cccc}
r_{11} & r_{12} & \ldots & r_{1 n} \\
r_{21} & r_{22} & \ldots & r_{2 n} \\
\vdots & \vdots & \vdots & \vdots \\
r_{m 1} & r_{m 2} & \ldots & r_{m n}
\end{array}\right], r_{x y}=\frac{S_{x y}}{S_{x} S_{y}}
$$

where $r_{x y}$ is the sample correlation coefficient, $S_{x y}$ is the sample covariance, $S_{x}$ is sample $X$ 's standard deviation, and $S_{y}$ is sample $Y$ 's standard deviation.

The data correlation has been visualized, as shown in Figure 4. The components of the vector presented are ship speed, distance, main engine revolution (M.E. Rev.), fuel consumption (Fuel Cons., which is the total quantity in a fixed time span), fuel consumption rate (F.C. Rate), M.E. power, EEOI, telegraph order command (Order), wind speed (Wind Spd.), wind direction (Wind Dir.), wave height (Wave Hgt.) and water flow speed (Flow Spd.). Analysis of data analytics has shown that five variables, including the telegraph order, engine power, fuel consumption, fuel consumption rate and engine revolution are strongly correlated with each other. Therefore, these variables were combined into one influencing factor, "M.E. Rev". According to Section 2.1, the ship speed and fuel consumption rate are the two output variables of the model. The water flow speed, wave height, wind direction and wind speed have different degrees of correlation with the outputs but have weak correlations with each other or other factors. Therefore, the number of dimensions of input variables finally reduced to 5 , including the engine revolution, wind speed, wind direction, wave height, and water flow speed. These variables were taken as the inputs to the neural network.

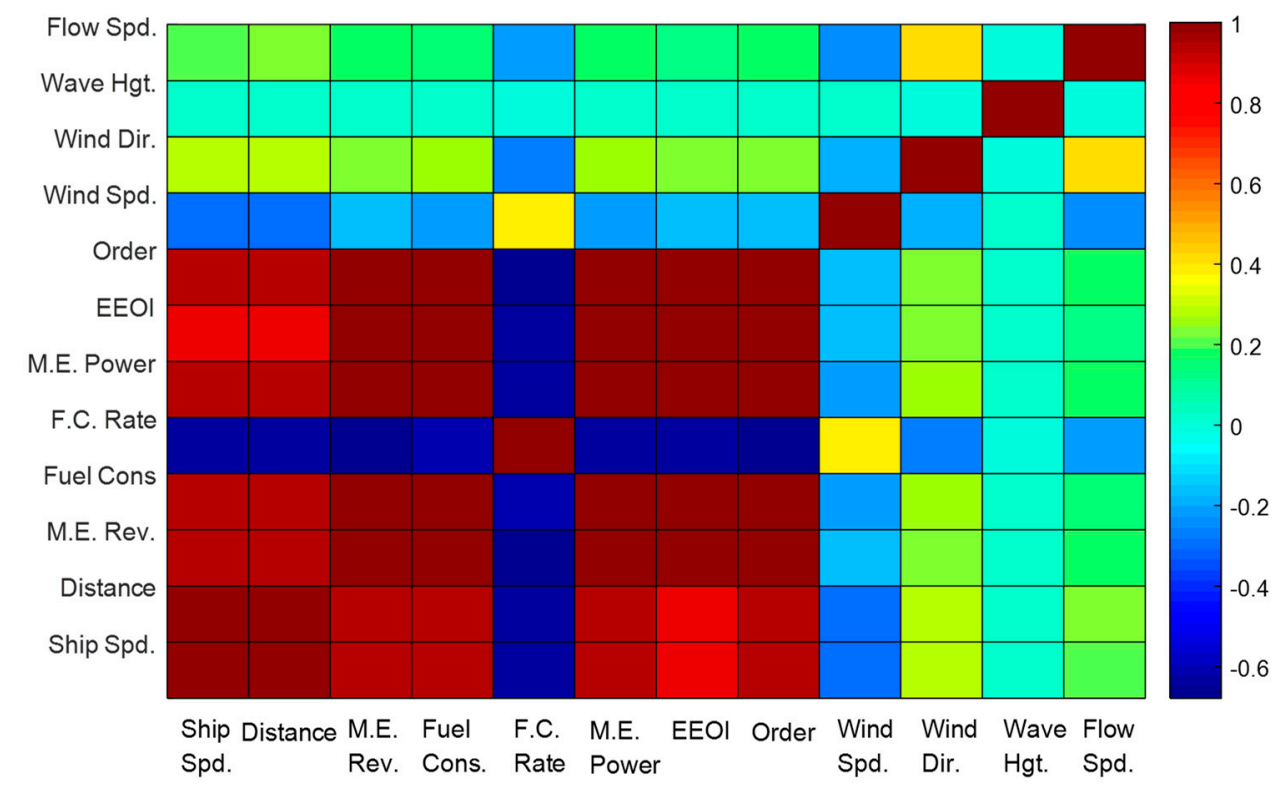

Figure 4. Data correlation diagram.

\subsection{Construction of the Neural Network}

\subsubsection{Basic Structure}

According to the previous section, the neural network has 5-dimensional inputs and 2-dimensional outputs. The classic 3-layer BP (Backward Propagation) neural network selected, and the number of hidden layers was calculated using an empirical formula, as shown in Equation (5):

$$
n_{h}=\sqrt{n_{i}+n_{o}}+l=\sqrt{5+2}+3=5,
$$


where $n_{h}$ is the number of neurons in the hidden layer, $n_{i}$ is the number of nodes in the input layer, $n_{0}$ is the number of nodes in the output layer, and $l$ is the number of layers. $n_{h}$ is generally a constant from 0 to 12. The network structure is shown in Figure 5. In this structure, the transfer function of the hidden layer is the Sigmoid function, and the transfer function of the output layer is a linear function.

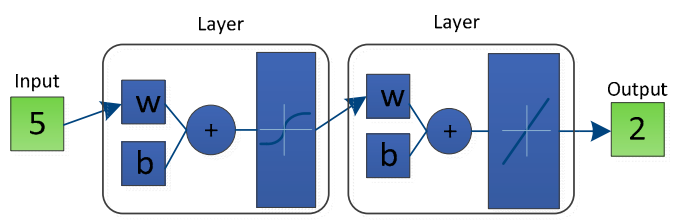

Figure 5. The network structure.

\subsubsection{Initial Structure Optimization by the Genetic Algorithm}

A genetic algorithm was applied to optimize the initial connection weights and thresholds which directly affect the approximation ability and adaptability of the network $[19,20]$. The genetic algorithm was used to globally optimize the initial connection weights and thresholds of each node in the EEOI prediction model.

The encoding method of the individual population in the genetic algorithm adopted a simple and efficient binary coding method. The coding length was set to 30. Each chromosome consisted of a piece of binary code of the connection weight and threshold, which are generally limited in the search space [21].

The parameters of the genetic algorithm were specifically set as follows-the fitness function was the mean square error between the actual output of the neural network and the expected output; the number of chromosomes was set to 50; the maximum number of iterations was set to 100; the number of variables was set to 42 ; the crossover rate of the chromosome was set to 0.92 ; and the mutation rate of the chromosome was set to 0.0238 .

The genetic algorithm performance tracking is shown in Figure 6. After 40 generations, the objective value was almost constant. The variation in the fitness value was small after 40 generations. Therefore, the result after 100 generations can be seen as the optimized value.

After 100 generations of inheritance, the initial weights and bias matrices of the BP network were obtained, as shown in Appendix A.1 Section. The optimized link weights and bias were assigned to the EEOI prediction model, and the optimized neural network has been trained using historical data to update the weights and bias.

\subsection{Training the Network}

The pretreated 9890 navigation data were used to train the neural network. The mean square errors of the expected and actual output values were taken as the total error signal. The error back propagation algorithm was used. The number of iterations was set to 10000 . The training was stopped at the 223th iteration when the mean square error reached $0.911 \times 10^{-7}$. The convergence speed was greatly improved. The training parameter curve is shown in Figure 7.

The BP neural network parameters after training were shown in Appendix A.2 Section. 

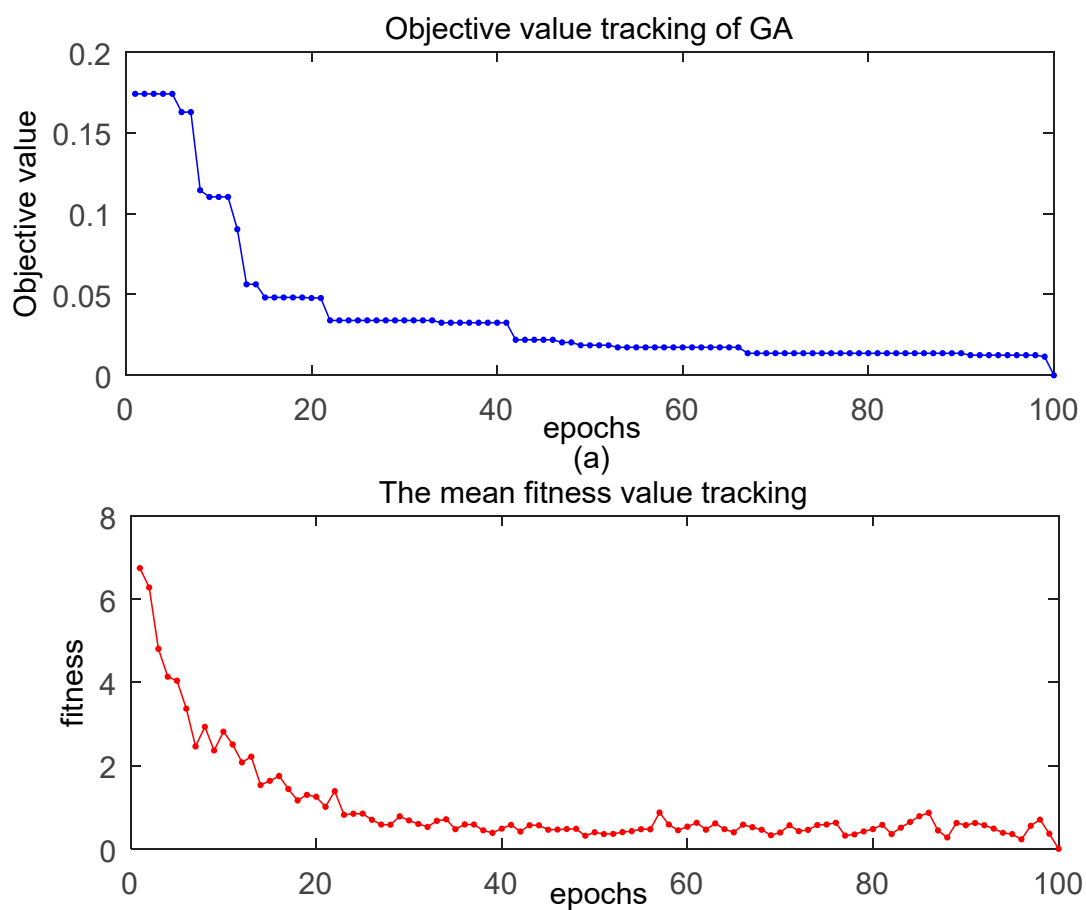

(b)

Figure 6. Genetic algorithm performance tracking. (a) Objective value tracking (b) The mean fitness value tracking.

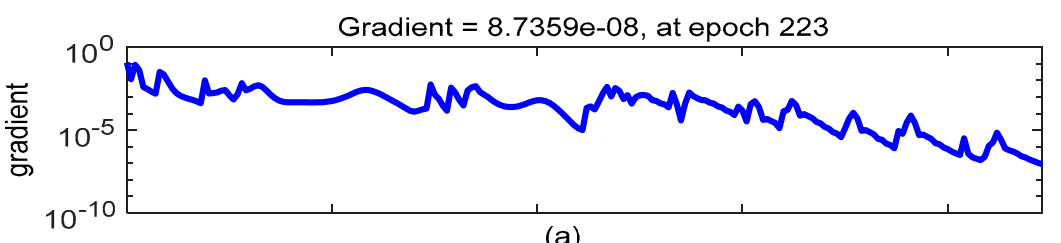

(a)

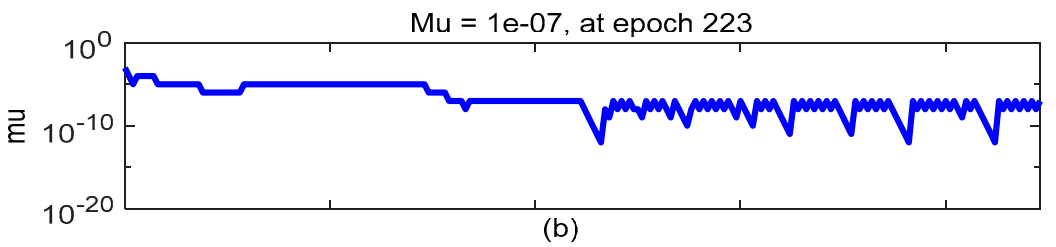

(b)

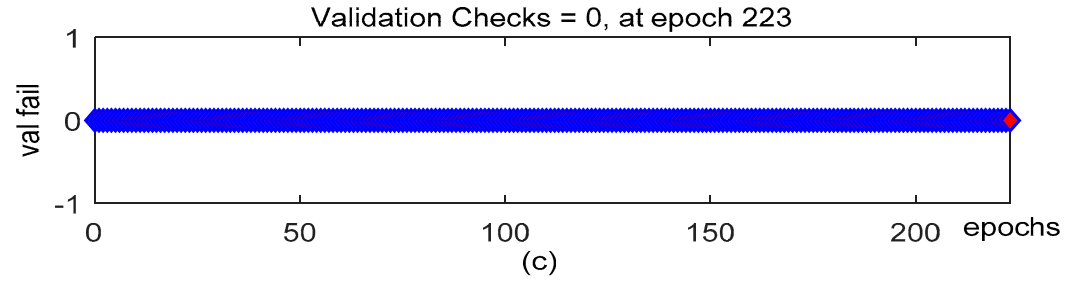

Figure 7. The training parameter curve. (a) Gradient (b) Mu (c) validation fail.

\section{Ship Propulsion Model}

The trained neural network can predict fuel consumption and ship speed on board. It can also be applied to the optimization method of EEOI. However, the optimized engine revolution cannot be directly used on board before it has been sufficiently validated. Therefore, a ship propulsion model comprising of a fixed pitch propeller driven by a low-speed direct reversion marine diesel engine was built in Simulink to rapidly verify the algorithm [22]. The propulsion model (see Figure 8) could provide some extra data for the neural network. In this model, the ME module represents the main 
engine, which is a large-scale, low-speed, two-stroke diesel. The prop module represents the propeller. The ship module models the ship motion. The resistance module is the model of ship's resistance when sailing. The wind/wave module simulates the wind and wave force. The Setting Unit is used to set orders to the model. The monitoring module is used for parameter observation.

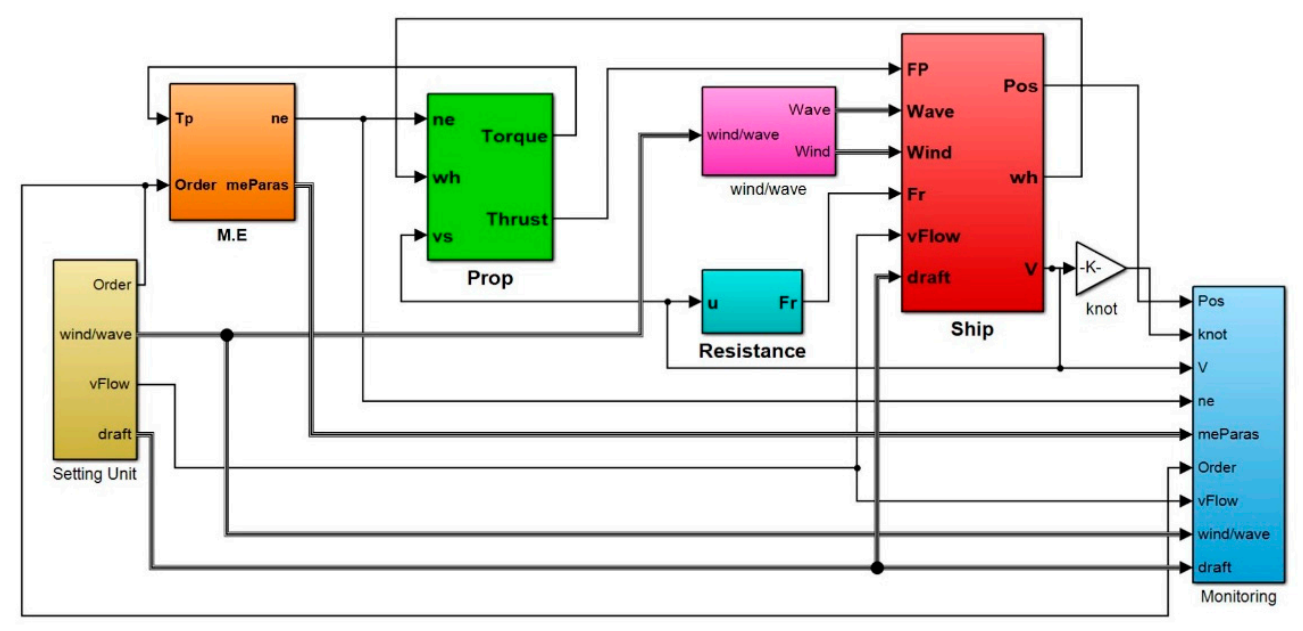

Figure 8. Ship propulsion model in Simulink.

\subsection{Main Engine}

The mean value diesel engine model used is a combination of the quasi-steady and volumetric models and it has been comprehensively used for non-linear control and state observations. Because of its faster computing speed, the model is widely used. In order to simulate maneuvering conditions, such as starting, braking and reversing, the model has to be modified to adapt to all-regime running conditions.

Under reversing working conditions, the engine revolution has to enter a zero crossing situation. The static friction torque, which is usually ignored under normal conditions, should be considered. Therefore, the modified friction model was introduced, as shown in Equation (6):

$$
T_{f}= \begin{cases}T_{f n}\left(\left|n_{e}\right|\right) * \operatorname{sgn}\left(n_{e}\right) & \left|n_{e}\right| \geq n_{s} \\ T_{e} & \left|n_{e}\right|<n_{s} \&\left|T_{e}\right|<T_{s}, \\ T_{s} * \operatorname{sgn}\left(T_{e}\right) & \text { others }\end{cases}
$$

where $T_{f}$ is the friction torque $(\mathrm{Nm}), T_{e}$ is the driven torque $(\mathrm{Nm})$, which is the sum of the indicated torque, starting torque, and propeller resistance torque, $T_{S}$ is the maximum static friction torque $(\mathrm{Nm})$, $T_{f n}$ is the viscous friction torque ( $\left.\mathrm{Nm}\right), n_{e}$ is the engine revolution (rpm), and $n_{s}$ is the speed dead zone for changing friction torque direction (rpm). For doing so, friction torque flutter is avoided.

Starting and braking is usually fulfilled by supplying compressed air into cylinders. According to a force analysis of the crank connecting rod mechanism [22], the mean torque value of compressed air for a multi-cylinder diesel can be defined as

$$
T_{s a}=\operatorname{sgn}(\text { cam }) \frac{D^{2}\left(p_{s a}-p_{s}\right) S_{t} N_{c y l}}{16}\left[\frac{3}{2}+\frac{1}{\lambda}\left(1-\sqrt{1-\frac{3}{4} \lambda^{2}}\right)\right],
$$

where cam is the direction of the air distributor cam, $p_{s a}$ is the starting air pressure (Pa), $p_{s}$ is the intake manifold pressure $(\mathrm{Pa}), S_{t}$ is the stroke $(\mathrm{m}), N_{c y l}$ is the number of cylinders, $\lambda$ is the ratio of the crank to the connecting rod, and $D$ is the diameter of the cylinder $(\mathrm{m})$. 


\subsection{Propeller}

A propeller has four quadrant working conditions that match ship motions. Those are known as-forward ship velocity/positive propeller rotation, forward velocity/negative rotation, backward velocity/negative rotation, and backward velocity/positive rotation. Figure 9 shows the thrust coefficient $k_{p}$ and torque coefficient $k_{m}$ as functions of the bounded advanced ratio.

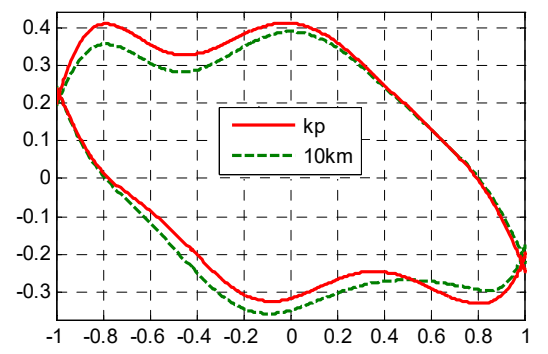

Figure 9. Propeller characteristics across four quadrants.

The bounded advanced ratio was defined as:

$$
\lambda_{p}=(1-w) v_{s} / \sqrt{(1-w)^{2} v_{s}^{2}+D_{p}^{2} n_{p}^{2}}
$$

where $\lambda_{p}$ is the bounded advanced ratio, $w$ is the wake factor, $v_{s}$ is the ship velocity $(\mathrm{m} / \mathrm{s}), D_{p}$ is the diameter of the propeller $(\mathrm{m})$, and $n_{p}$ is the rotational speed of the propeller (rev/s), which is equal to that of the engine, owing to the propeller directly connecting to the engine.

The torque $\left(T_{p}\right)$ and thrust $\left(P_{p}\right)$ of propeller were defined as:

$$
\begin{aligned}
& T_{p}=k_{m}(1-t) \rho D_{p}^{3}\left[(1-w)^{2} v_{s}^{2}+D_{p}^{2} n_{p}^{2}\right] . \\
& P_{p}=k_{p}(1-t) \rho D_{p}^{2}\left[(1-w)^{2} v_{s}^{2}+D_{p}^{2} n_{p}^{2}\right],
\end{aligned}
$$

where $t$ is the thrust-deduction fraction, and $\rho$ is the density of sea water $\left(\mathrm{kg} / \mathrm{m}^{3}\right)$.

\subsection{Ship Longitudinal Motion}

In this study, only longitudinal motion has been considered. Hence ship velocity was calculated by

$$
\dot{v}_{s}=\left(P_{p}-R_{f}\right) /\left(m+m_{\lambda}\right),
$$

where $m$ is the mass of the ship $(\mathrm{kg})$, and $m_{\lambda}$ is the mass of the entrained water $(\mathrm{kg})$. The value of $m_{\lambda}$ depends on the mass and velocity of the ship. Usually, it may be 0.2 times the mass of the ship when the ship is sailing at a normal speed. $R_{f}$ is defined as the resistance of the ship $(\mathrm{N})$ and it is defined as:

$$
R_{f}=-C_{t} \rho S v_{s}^{2},
$$

where $C_{t}$ is the total friction coefficient, $S$ is the wet area of the ship $\left(\mathrm{m}^{2}\right)$ calculated on the basis of the ship's principal dimensions.

\subsection{Wind and Wave Forces}

Wind and wave forces may affect ship speed. However, it is difficult and time consuming to build an exact wind and wave force model. Moreover, instantaneous force waveforms of wind and wave have no significant influences on the ship's longitudinal motion. The wind speed can be seen as superposition of the mean wind speed and disturbance wind speed. Furthermore, the disturbance wind speed can be seen as white noise. So, the wind model can be simplified. On this basis a simplified 
model, which is widely used in ship maneuvering simulator, was implemented here. The wind force has been related to the wind speed, angle, and area of the ship exposed to wind, as shown in Equation (13).

$$
R_{w}=0.5 \rho_{a} A_{w} U_{w} C_{w}\left(\alpha_{w}\right),
$$

where $R_{w}$ is the wind resistance, $(\mathrm{N}), \rho_{a}$ is the air density, $\left(\mathrm{kg} / \mathrm{m}^{3}\right), A_{w}$ is the ship's orthographic projection area above the water line, $\left(\mathrm{m}^{2}\right), U_{w}$ is the relative wind speed $(\mathrm{m} / \mathrm{s}), C_{w}\left(\alpha_{w}\right)$ is the wind force coefficient, and $\alpha_{w}$ is the relative wind direction angle (deg).

When modeling the wave force, only the first-order wave force was considered and accordingly the resistance of the wave was defined as:

$$
R_{v}=2 a B \frac{\sin b \cdot \sin c}{c} s(t),
$$

where $a=\rho g\left(1-e^{-k d}\right) / k^{2}, b=k L / 2 \cos \chi, c=k B / 2 \sin \chi, s(t)=(k h / 2) \sin \left(\omega_{e} t\right), k=2 \pi / \lambda_{w} . \lambda_{w}$ is the wavelength $(\mathrm{m}), \chi$ is the relative wave direction, and $\omega_{e}$ is the encountered frequency of the ship and waves $(\mathrm{Hz})$.

\section{Optimization of M.E. Revolutions}

The trained network was used to construct the objective function. The main engine (ME) revolution was taken as the optimizing variable. The fitness function is the difference between the actual and predicted EEOI values after optimization. The fitness function FitV is defined as shown in Equation (15):

$$
\begin{gathered}
\text { FitV }=\max \left[E E O I-E E O I^{\prime}\right]=\max \left[E E O I-G A B P\left(n_{e}\right)\right] \\
=\max \left[E E O I-\frac{C_{f}^{*} F_{c, p r e} * 1853.2}{M_{\text {carg }} * D_{\text {pre }}}\right]
\end{gathered}
$$

where EEOI' is the last value of $E E O I$, which is predicted by $\operatorname{GABP}\left(n_{e}\right)$, which represents the BP $\mathrm{NN}$ built in Section 2, $n_{e}$ is the M.E. RPM, $C_{f}$ is the carbon dioxide conversion factor, $M_{\text {cargo }}$ is the ship-loading quantity $(\mathrm{t}), F_{c, p r e}$ is the predicted fuel consumption $(\mathrm{f})$, and $D_{\text {pre }}$ is the predicted sailing distance $(\mathrm{nm})$.

Three steps were taken to build fitness function. The first step was to predict the engine revolution and fuel consumption rate using the neural network model built in Section 2. The second step was to integrate them to determine the sailing distance and the fuel consumption during sailing. The last step was to calculate the difference between the actual EEOI and the predicted EEOI after adjusting the engine revolution. After the optimization was finished, the optimized main engine revolution was set to the real engine. The ship propulsion model was applied to represent the actual ship and the actual engine. The network was trained online at the same time of optimization. The entire EEOI index dynamic optimization algorithm flow is shown in Figure 10.

After the objective function was established, the genetic algorithm was applied to perform global optimization. The boundary condition was that the engine revolution was controlled between 80 and $130 \mathrm{rpm}$, and the power was controlled between 75\% and 100\% MCR (Maximum Continuous Rating point). The navigation environment was set as shown in Table 1.

Table 1. Initial value of the navigation environment.

\begin{tabular}{cc}
\hline Parameter & Value \\
\hline Wind speed $(\mathrm{m} / \mathrm{s})$ & 9 \\
Wind angle $(\mathrm{deg})$. & 62 \\
Wave height $(\mathrm{m})$ & 5 \\
Water flow speed & -6 \\
Main engine revolution $(\mathrm{rpm})$ & 10.3 \\
\hline
\end{tabular}




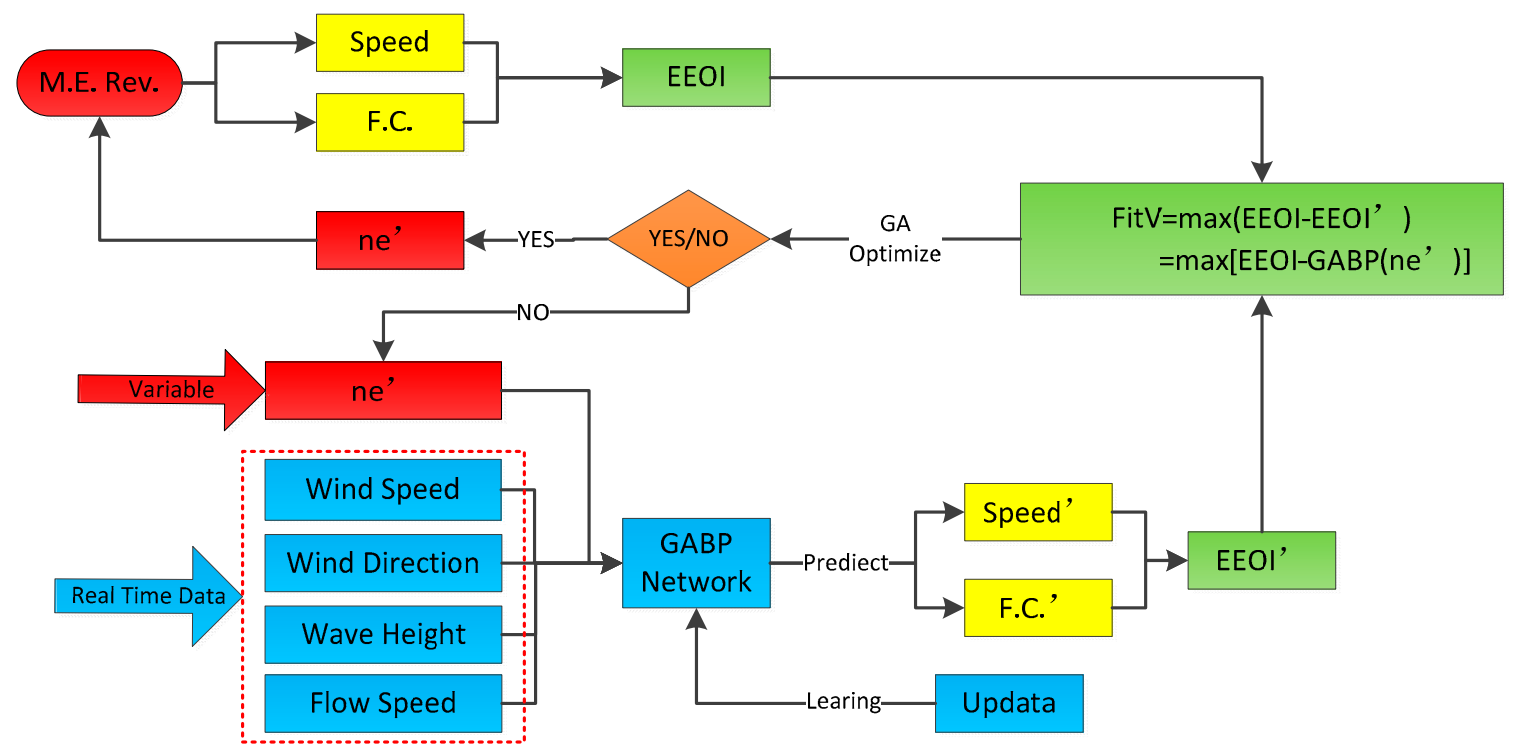

Figure 10. The dynamic optimization algorithm flow.

The EEOI dynamic optimization algorithm was used to optimize the engine revolution. The algorithm performance tracking is shown in Figure 11. The predicted EEOI was lowest when the engine revolution was kept at $122 \mathrm{rpm}$. Therefore, the optimized engine revolution was used to set the real engine as the new order.

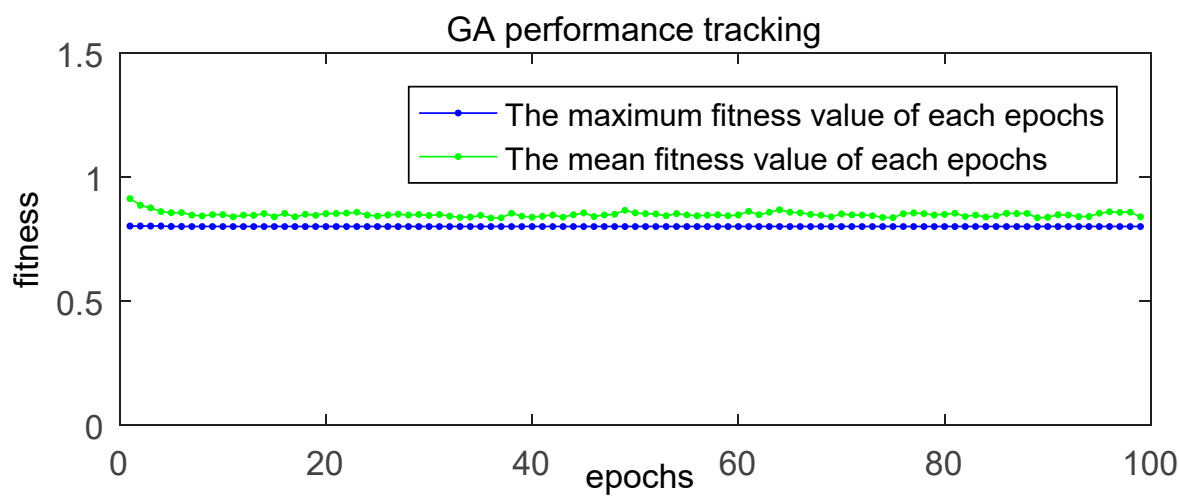

(a)

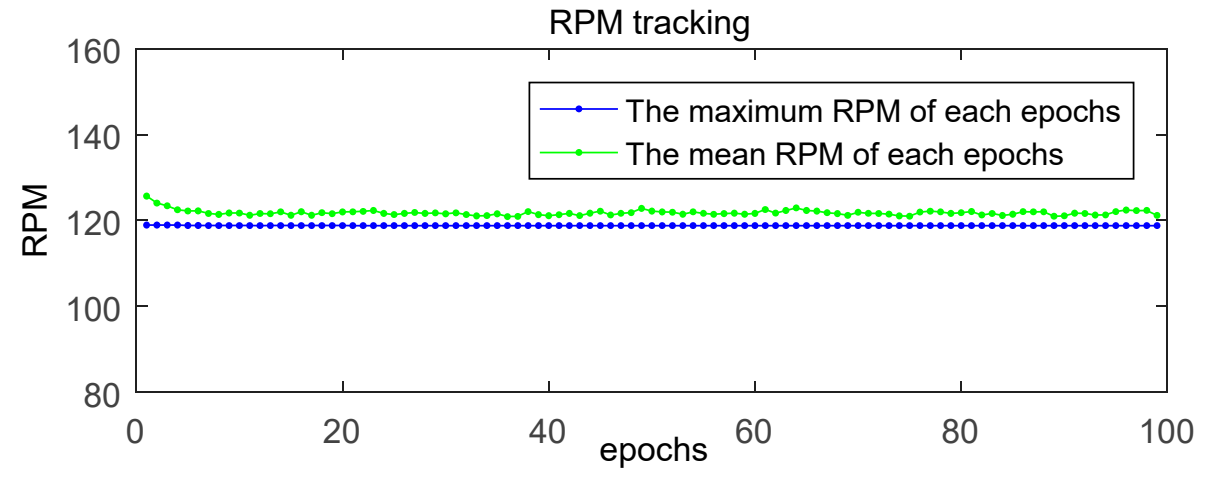

(b)

Figure 11. Performance tracking of the engine revolution optimization algorithm. (a) GA performance tracking (b) RPM tracking. 


\section{Results}

The results presented in this paper are based on the training ship "YUMING," which belongs to Shanghai Maritime University. "YUMING" is a bulk carrier and can accommodate 160 personnel. Its parameters are shown in Table 2.

Table 2. Parameters of the YUMING vessel.

\begin{tabular}{cccc}
\hline Parameter & Value & Parameter & Value \\
\hline Length $(\mathrm{m})$ & 189.9 & Breadth $(\mathrm{m})$ & 32.3 \\
Depth $(\mathrm{m})$ & 15.7 & Block Coefficient & 0.85 \\
Design draft $(\mathrm{m})$ & 10.3 & Design Displacement $(\mathrm{t})$ & 58123.9 \\
Type of M.E & 6 S50ME & Rated Revolution $(\mathrm{rev} / \mathrm{min})$ & 127 \\
Stroke $(\mathrm{m})$ & 2 & Rated Power $(\mathrm{kW})$ & 7948 \\
Diameter of propeller $(\mathrm{mm})$ & 5850 & Number of blades & 4 \\
\hline
\end{tabular}

\subsection{Simulation of the Ship Propulsion Model}

To verify the performance of the model, simulations were conducted under the same navigation environments experienced by YUMING during sea trial. Accordingly, the ship forward draft and aft draft were set to $7.10 \mathrm{~m}$ and $7.95 \mathrm{~m}$, respectively. The revolution of the main engine was set to $126.5,122,114.8$, and 100.2rev/min, respectively. A comparison demonstrating good agreement of data that resulted from the actual ship sea trials and simulation is shown in Table 3. Accordingly, the ship propulsion model may be considered credible.

Table 3. Comparison between the simulation model and real ship data.

\begin{tabular}{cccccccccc}
\hline & \multicolumn{4}{c}{ Navigation Data } & & Actual & Simu. & Actual & Simu. \\
\hline Load & $\begin{array}{c}\text { Engine } \\
\text { Rev } \\
(\mathbf{R P M})\end{array}$ & $\begin{array}{c}\text { Wind } \\
\text { Speed } \\
(\mathbf{m} / \mathbf{s})\end{array}$ & $\begin{array}{c}\text { Wind } \\
\text { Direction } \\
(\mathbf{})\end{array}$ & $\begin{array}{c}\text { Wave } \\
\text { Height } \\
(\mathbf{m})\end{array}$ & $\begin{array}{c}\text { Flow } \\
\text { Speed } \\
(\mathbf{m} / \mathbf{s})\end{array}$ & $\begin{array}{c}\text { Power } \\
(\mathbf{k W})\end{array}$ & $\begin{array}{c}\text { Power } \\
(\mathbf{k W})\end{array}$ & $\begin{array}{c}\text { Ship } \\
\text { Speed } \\
(\mathbf{k n})\end{array}$ & $\begin{array}{c}\text { Ship } \\
\text { Speed } \\
(\mathbf{k n})\end{array}$ \\
\hline $100 \%$ & 126.5 & 7.0 & 300 & 0.2 & 0.4 & 6986.5 & 7073 & 14.165 & 14.12 \\
$90 \%$ & 122 & 6.0 & 30 & 1 & -0.6 & 6390.5 & 6337 & 13.748 & 13.61 \\
$75 \%$ & 114.8 & 7.7 & 80 & 0.4 & 0.2 & 5335.0 & 5270 & 12.700 & 12.53 \\
$50 \%$ & 100.2 & 8.1 & 90 & 0.3 & -0.4 & 3508.0 & 3506 & 10.945 & 10.58 \\
\hline
\end{tabular}

\subsection{Results of Optimization}

The EEOI prediction model, ship propulsion model and genetic optimization algorithm were used to simulate the whole closed-loop optimization algorithm of the main engine revolution under different environmental conditions. The ship was assumed to operate in ballast condition, with forward and aft drafts were set according to the sea trial report. The cycle time, shown in Equation 2, was set to $3600 \mathrm{~s}$. Simulations were conducted under different environmental conditions. Three kinds of engine revolution were used under the same navigation environment, including un-optimized engine revolution, optimized engine revolution, and engine revolutions lower than the optimized level (see Table 4). 
Table 4. Energy Efficiency Operational Indicator (EEOI) optimization results.

\begin{tabular}{|c|c|c|c|c|c|c|c|c|c|c|}
\hline \multirow[b]{2}{*}{ No. } & \multicolumn{4}{|c|}{ Navigation Environment } & \multicolumn{2}{|c|}{ Normal } & \multicolumn{2}{|c|}{ Optimized } & \multicolumn{2}{|c|}{ Decreased } \\
\hline & $\begin{array}{c}\text { Wind } \\
\text { Speed } \\
(\mathrm{m} / \mathrm{s})\end{array}$ & $\begin{array}{l}\text { Wind } \\
\text { Angle } \\
\left({ }^{\circ}\right)\end{array}$ & $\begin{array}{c}\text { Wave } \\
\text { Height } \\
\text { (m) }\end{array}$ & $\begin{array}{c}\text { Flow } \\
\text { Speed } \\
(\mathrm{m} / \mathrm{s})\end{array}$ & $\begin{array}{c}\text { Rev. } \\
\text { (rpm) }\end{array}$ & EEOI & $\begin{array}{c}\text { Rev. } \\
\text { (rpm) }\end{array}$ & EEOI & $\begin{array}{c}\text { Rev. } \\
(\mathrm{rpm})\end{array}$ & EEOI \\
\hline 1 & 9 & 62 & 5 & -6 & 127 & 9.66 & 122 & 6.79 & 119 & 9.01 \\
\hline 2 & 3 & -12 & 2.4 & 3.5 & 127 & 7.23 & 121 & 6.44 & 120 & 6.50 \\
\hline 3 & 0 & 0 & 0.2 & -2.1 & 127 & 7.92 & 121 & 6.53 & 119 & 7.01 \\
\hline 4 & 2.1 & 120 & 1.5 & 1.5 & 127 & 7.35 & 123 & 6.50 & 120 & 6.54 \\
\hline 5 & 5 & -55 & 2.0 & -0.9 & 127 & 7.86 & 120 & 6.56 & 117 & 6.68 \\
\hline 6 & 1.7 & -175 & 1.3 & 1.0 & 127 & 7.43 & 122 & 6.51 & 120 & 6.58 \\
\hline 7 & 4.5 & 97 & 3.2 & 2.3 & 127 & 7.32 & 123 & 6.44 & 120 & 6.50 \\
\hline 8 & 6.1 & 135 & 2.3 & -1.5 & 127 & 7.75 & 122 & 6.43 & 119 & 6.83 \\
\hline 9 & 3.8 & 21 & 4.2 & 2.9 & 127 & 7.35 & 121 & 6.54 & 120 & 6.54 \\
\hline 10 & 7.1 & 61 & 2.2 & -1.5 & 127 & 8.10 & 122 & 6.86 & 118 & 7.02 \\
\hline
\end{tabular}

(The "Normal" column means that the ship sails on an un-optimized engine revolution. The "Optimized" column means that the ship sails on an optimized engine revolution. The "Decreased" column means that the ship sails on an engine revolution lower than the optimized.)

\section{Discussion}

Under the same environmental conditions and the same main engine revolution, the simulation data of the ship propulsion model showed satisfactory agreement with the actual sea trial report of the ship (see Table 3). Therefore, the simulation model for ship longitudinal motion is reliable and can be used to verify the EEOI optimization algorithm.

As shown in Table 4, the EEOI value with optimized engine speed has been at its lowest under different navigation conditions, even though the "Decreased" column had corresponds to lower engine revolutions. The optimized revolution is lower than the normal revolution but higher than decreased revolution. This shows the optimized engine revolutions are the best in a local revolution range. Moreover, the optimized engine revolutions are different in different navigation environments. That shows the optimization method is valuable in different environment conditions. Therefore, there are reasons to believe that the optimization concept and method used in this paper can help to improve the EEOI within a certain revolution range. In the future, different cycle times will be tested to find the best cycle time. Additionally, a more accurate wind and wave model will be introduced into the simulation.

Author Contributions: Conceptualization, C.S., C.L. and H.W.; methodology, H.W.; software, Y.Z. and H.W.; validation, C.S., H.W. and Y.Z.; formal analysis, Y.Z.; data curation, Y.Z.; writing-original draft preparation, H.W. and Y.Z.; writing - review and editing, C.S. and C.L.; visualization, Y.Z.; project administration, C.S.

Funding: This research received no external funding.

Conflicts of Interest: The authors declare no conflict of interest.

\section{Appendix A.}

Appendix A.1. Initial Parameters Optimized by the Genetic Algorithm

After 100 generations of inheritance (see Figure 6), the input layer weight of the BP network was:

$$
W_{1}=\left[\begin{array}{ccccc}
-1.248439973 & -2.803119181 & -2.315609078 & -2.734189672 & -1.009229688 \\
-2.153366518 & -1.223545805 & 1.233045222 & -0.006755213 & -2.637285875 \\
-0.706587596 & -1.552185432 & -1.70930286 & -1.426524951 & -1.544026107 \\
-2.536474959 & 0.3447923 & -1.428494005 & -0.33143305 & 1.660091796 \\
-0.298490393 & 0.033244195 & -0.231048075 & -2.173095702 & 1.011001131
\end{array}\right]
$$


The bias of the input layer of the BP network was:

$$
B_{1}=\left[\begin{array}{c}
-2.356582358 \\
-0.377748027 \\
-2.597593093 \\
-0.119641422 \\
0.556043876
\end{array}\right]
$$

The weight of the hidden layer of the BP network was:

$$
W_{2}=\left[\begin{array}{ccccc}
-1.295896113 & -0.313681643 & 2.461507838 & -1.6802041 & 0.184608839 \\
1.097034432 & 0.456472493 & 0.432887192 & -2.590474197 & -0.072519056
\end{array}\right]
$$

The bias of the hidden layer of the BP network was:

$$
B_{2}=\left[\begin{array}{c}
0.691785557 \\
0.93183824
\end{array}\right]
$$

Appendix A.2. Training Results of the Neural Network

The BP neural network parameters after training (see Figure 7) were as follows: The updated connection weight between the input and hidden layer nodes of the BP neural network was:

$$
W_{1}=\left[\begin{array}{ccccc}
18.48441067 & -166.2131336 & -18.31794663 & -1.945587221 & -180.3705467 \\
1.670072096 & -5.701199595 & 1.046077173 & -0.113205799 & -0.387741131 \\
1.817608606 & -0.411062349 & -1.800417414 & 0.014945118 & 0.010554454 \\
-1.72338033 & 0.342933773 & -0.045117079 & 0.005803816 & 0.033218607 \\
1.252456707 & -0.5590336 & 2.126794179 & -0.033308813 & -0.158627126
\end{array}\right]
$$

The updated bias of the input layer of the BP network was:

$$
B_{1}=\left[\begin{array}{c}
89.86764057 \\
-0.535052367 \\
-1.096480206 \\
2.872470465 \\
-2.594345004
\end{array}\right]
$$

The updated connection weight between hidden and output layer nodes of the BP network was:

$$
W_{2}=\left[\begin{array}{ccccc}
-0.073153078 & -0.147220138 & 2.212682572 & 3.174568662 & 2.074976114 \\
-0.006980749 & -0.247812464 & 0.153286346 & -5.545652166 & 0.129901491
\end{array}\right]
$$

The updated bias of the hidden layer of the BP network was:

$$
B_{2}=\left[\begin{array}{c}
-3.461900104 \\
5.294246266
\end{array}\right]
$$

\section{References}

1. International Maritime Organization. Reduction of GHG Emissions from Ships Third IMO GHG Study 2014 Final Report; MEPC 67/INF.3: London, UK, 2014.

2. Corbett, J.J.; Wang, H.; Winebrake, J.J. The effectiveness and costs of speed reductions on emissions from international shipping. Transp. Res. Part D Transp. Environ. 2009, 14, 593-598. [CrossRef] 
3. Lindstad, H.; Asbjørnslett, B.E.; Strømman, A.H. Reductions in greenhouse gas emissions and cost by shipping at lower speeds. Energy Policy 2011, 39, 3456-3464. [CrossRef]

4. Hirdaris, S.; Cheng, F. The Role of Technology in Green Ship Design. In Proceedings of the 11th International Marine Design Conference, Glasgow, UK, 11-14 June 2012; Volume 1. [CrossRef]

5. Psaraftis, H.N.; Kontovas, C.A. Speed models for energy-efficient maritime transportation: A taxonomy and survey. Transp. Res. Part C Emerg. Technol. 2013, 26, 331-351. [CrossRef]

6. Norstad, I.; Fagerholt, K.; Laporte, G. Tramp ship routing and scheduling with speed optimization. Transp. Res. Part C Emerg. Technol. 2011, 19, 853-865. [CrossRef]

7. Wang, S.; Meng, Q. Sailing speed optimization for container ships in a liner shipping network. Transp. Res. Part E Logist. Trans. Rev. 2012, 48, 701-714. [CrossRef]

8. Fang, M.; Lin, Y. The optimization of ship weather-routing algorithm based on the composite influence of multi-dynamic elements (II): Optimized routings. Appl. Ocean Res. 2015, 50, 130-140. [CrossRef]

9. Chang, C.; Wang, C. Evaluating the effects of speed reduce for shipping costs and $\mathrm{CO}_{2}$ emission. Transp. Res. Part D Transp. Environ. 2014, 31, 110-115. [CrossRef]

10. Bialystocki, N.; Konovessis, D. On the estimation of ship's fuel consumption and speed curve: A statistical approach. JOES 2016, 1, 157-166. [CrossRef]

11. Petersen, J.P.; Winther, O.; Jacobsen, D.J. A Machine-Learning Approach to Predict Main Energy Consumption under Realistic Operational Conditions. Ship Technol. Res. 2012, 59, 64-72. [CrossRef]

12. Pedersen, B.P.; Larsen, J. Prediction of Full-Scale Propulsion Power using Artificial Neural Networks. In Proceedings of the 8th International Conference on Computer and IT Applications in the Maritime Industries, Budapest, Hungary, 15-17 May 2009.

13. Kai, W.; Yan, X.; Yuan, Y.; Feng, L. Real-time optimization of ship energy efficiency based on the prediction technology of working condition. Transp. Res. Part D Transp. Environ. 2016, 46, 81-93.

14. International Maritime Organization. Guidelines for Voluntary Use of the Ship Energy Efficiency Operational Indicator; MEPC 59/Circ. 684: London, UK, 2009.

15. Hariri, R.H.; Fredericks, E.; Bowers, K. Uncertainty in big data analytics: Survey, opportunities, and challenges. J. Big Data 2019, 6, 44. [CrossRef]

16. Veiga, J.; Enes, J.; Expósito, R.R.; Touriño, J. BDEv 3.0: Energy efficiency and microarchitectural characterization of Big Data processing frameworks. Future Gener. Comput. Syst. 2018, 86, 565-581. [CrossRef]

17. Desai, N.; Seghouane, A.; Palaniswami, M. Algorithms for two dimensional multi set canonical correlation analysis. Pattern Recogn. Lett. 2018, 111, 101-108. [CrossRef]

18. Yi, Z.; Teng, L.; Li, K.; Zhang, J. Improved Visual Correlation Analysis for Multidimensional Data. J. Vis. Lang. Comput. 2017, 41, 121-132.

19. Yu, S.; Zhu, K.; Diao, F. A dynamic all parameters adaptive BP neural networks model and its application on oil reservoir prediction. Appl. Math. Comput. 2008, 195, 66-75. [CrossRef]

20. Han, B.; Bian, X. A hybrid PSO-SVM-based model for determination of oil recovery factor in the low-permeability reservoir. Petroleum 2018, 4, 43-49. [CrossRef]

21. Taheri, M.; Mohebbi, A. Design of artificial neural networks using a genetic algorithm to predict collection efficiency in venturi scrubbers. J. Hazard. Mater. 2008, 157, 122-129. [CrossRef] [PubMed]

22. Wang, H.; Tang, H. Modeling and Simulation of diesel propulsion system in maneuvering navigation condition. Appl. Mech. Mater. 2012, 128-129, 1168-1172. [CrossRef]

(C) 2019 by the authors. Licensee MDPI, Basel, Switzerland. This article is an open access article distributed under the terms and conditions of the Creative Commons Attribution (CC BY) license (http://creativecommons.org/licenses/by/4.0/). 